\title{
Mulemba
}

Revista Angolana de Ciências Sociais

\section{A classificação etnográfica dos povos de Angola (1. parte)}

Classification ethnography of the people of Angola (Part I)

\section{Virgílio Coelho}

\section{(2) OpenEdition}

Journals

\section{Edição electrónica}

URL: https://journals.openedition.org/mulemba/473

DOI: $10.4000 /$ mulemba.473

ISSN: 2520-0305

\section{Editora}

Edições Pedago

\section{Edição impressa}

Data de publição: 1 maio 2015

Paginação: 203-220

ISSN: 2182-6471

\section{Refêrencia eletrónica}

Virgílio Coelho, «A classificação etnográfica dos povos de Angola (1. a parte)», Mulemba [Online], 5 (9) |

2015, posto online no dia 28 novembre 2016, consultado o 28 juin 2022. URL: http://

journals.openedition.org/mulemba/473 ; DOI: https://doi.org/10.4000/mulemba.473

Este documento foi criado de forma automática no dia 26 janeiro 2021.

Tous droits réservés 


\section{A classificação etnográfica dos povos de Angola (1. a parte)}

Classification ethnography of the people of Angola (Part I)

\section{Virgílio Coelho}

\section{NOTA DO EDITOR}

Recepção do manuscrito: 15/01/2015

Conclusão da revisão: 10/03/2015

Aceite para publicação: 25/03/2015

\section{NOTA DO AUTOR}

A ideia do presente levantamento e reflexão começou por ser pensada durante o seminário sobre «Diversidade étnica e integração», orientado pelo Professor Doutor Víctor Kajibanga, no âmbito do doutoramento em Ciências Sociais da Faculdade de Ciências Sociais (FCS) da Universidade Agostinho Neto (UAN).

\section{Introdução}

1 Com a presente reflexão pretendo efectuar um levantamento o mais exaustivo possível sobre a «classificação étnica» dos povos de Angola, que me levará inicialmente até aos anos de 1962-1963, período em que foi elaborado o «Esboço da Carta Étnica de Angola», sob a direcção do etnólogo Carlos Lopes Cardoso, do Departamento de Etnologia e Etnografia do Instituto de Investigação Científica de Angola (IICA), um documento que praticamente se tornou a síntese geral da cartografia dos povos de Angola, o qual, segundo Mesquitela Lima, vinha sendo melhorado de ano para ano; e, por fim, aos levantamentos efectuados por José Redinha (1960-1975), que, para este caso específico, 
trabalhou sempre de forma independente. Até se ter chegado a esses documentos sínteses, eram já conhecidos outros levantamentos, cujas informações começaram a ser recolhidas desde os fins do século XIX.

2 A utilização do «Esboço da Carta Étnica de Angola», ou, melhor dito, da classificação etnográfica dos povos de Angola, será feita em duas partes, sendo a primeira relativa ao período colonial e a segunda dizendo respeito a sua utilização no período pósindependente do país. Ao fazer esses levantamentos, pretendo mostrar as razões da sua utilidade tanto num como noutro período citado.

3 Mas, curiosamente, vamos iniciar este artigo não com um antropólogo como seria de desejar, mas com um historiador, René Pélissier. Este autor francês pode ser considerado como um dos maiores especialistas da história da resistência dos povos de Angola, em fins do século XIX e início do século XX, quando os portugueses, incentivados pelas conclusões saídas da Conferência de Berlim, na qual os países imperiais decidiram dividir entre si os territórios da África. Para não perder a parte que lhe julgava caber do espólio africano, os portugueses decidiram ocupar através da força os territórios que entendiam ser seu de pleno direito, pelos contactos seculares anteriormente estabelecidos, combatendo os povos encontrados e procurando destruir as suas estruturas socioeconómicas e políticas. Deste modo empreenderam acções sistemáticas contra os povos que intentaram fazer-lhes frente, esforços de guerra esses que denominaram «campanhas de pacificação» dos povos «indígenas», «selvagens», «primitivos» de Angola. Ora Pélissier foi justamente o historiador que dedicou uma boa parte do seu tempo a documentar, analisar e a escrever sobre a história da "resistência» desses povos, que estavam convictos do dever de não ceder aos intentos portugueses, para não perderem as suas terras e a independência de que tanto prezavam e haviam herdado dos seus antepassados.

É por isso que para estudar e documentar esses povos que lutaram avidamente para não perder a liberdade e as suas terras, René Pélissier utilizou esse recurso cartográfico e informativo sobre os «grupos étnicos» de Angola, encontrados no «Esboço» referido, produzido pelo IICA e apontando a data da sua produção como sendo 1964. Ao publicálo, esse recurso documental passa assim a ser um dos documentos mais conhecidos acerca da classificação étnica de Angola (cf. PÉLISSIER 1977: 15-16; 1978: 14-15; 1986, II: 337-338).

\section{Acerca dos inventários étnicos}

5 Pode dizer-se que os estudos classificativos sobre os povos de Angola devem-se sobretudo aos contributos dos missionários e administradores coloniais, já que trabalhos dos profissionais da etnologia e etnografia só apareceram muito mais tarde, sobretudo com o IICA, corroborando e acrescentando aqueles. Assim, no inventário que denominou «divisão etnográfica» da "população nativa da província» de Angola, o missionário metodista Héli Chatelain $(1894,1964)$ explica que «os limites dos distritos coincidem em grande parte com os das nações que constituem a população nativa da província» (1964: 75). Em seu entender, a «nação do Congo ocupa a maior parte do distrito do Congo, mas cobre também a parte norte do distrito de Luanda. Este último é ocupado pela nação de Angola (A-mbundu) cujo nome se estendeu a toda a província» (id., ibidem). Por sua vez, o «[...] distrito de Benguela é todo ocupado pela nação Ovi-mbundu e tribos aliadas», enquanto que as «[...] populações do distrito de Moçamedes não parecem formar uma unidade étnica, mas 
diferem pouco dos Ovi-mbundu, embora muitos tenham mais afinidades com os grupos parentes Ova-Herero e Ova-Ndonga das possessões alemães» (id., ibidem). Ademais, antes de indicar quais as tribos que compõem as referidas nações, este autor conclui enunciando que os «[...] povos para além do Cuango e os da bacia do Zambeze não são ainda administrados pelas autoridades portuguesas nem compreendidos em qualquer dos distritos acima mencionados» (1894; 1964: 76).

6 Nesse seu trabalho publicado em inglês nos Estados Unidos da América em fins do século XIX, mais exactamente em 1894 (com tradução portuguesa datada de 1964: 75-79) Héli Chatelain dá um grande contributo ao conhecimento sobre os povos que por essa época viviam no vasto território que depois será a Angola colonial, indicando inclusive quais eram os povos que ainda estavam independentes da administração colonial portuguesa e esse seu inventário não deve ter passado despercebido do Secretário dos Negócios Indígenas e Curador Geral da Província de Angola, José de Oliveira Ferreira Diniz, que na década de 1910 foi encarregado pelo governador geral Norton de Matos de efectuar estudos tendentes ao «conhecimento dos usos e costumes dos indígenas como base primordial da orientação a seguir na administração e política indígena», tarefa essa, entendida na ocasião como «um dos ramos de serviço mais importantes da colónia» (DINIZ 1918: V).

$7 \quad 0$ trabalho principal de Ferreira Diniz denomina-se Populações indígenas de Angola, sendo datado de 1918; foi, portanto, publicado cerca de 24 anos depois da obra de Chatelain, no entanto, não há nenhuma referência a este autor. Segundo Ferreira Diniz, na primeira parte dessa obra «descrevemos os usos e costumes das tribus de raça negra, fazendoo para algumas separadamente e para outras em conjunto atendendo a que as suas afinidades, pela origem, quási completa unidade filológica e a inteira semelhança de usos e costumes só nos levaria, separando-as, a fastidiosas repetições. [...] Na segunda parte apresentamos o estudo das tribus da raça Boschjman. [...] Na terceira parte fazemos o estudo etnológico ou de comparação das populações indígenas, procurando deduzir ao mesmo tempo os princípios de legislação $e$ administração que, mais adequadamente, deveremos estabelecer para as mesmas populações» (DINIZ 1918: VI-VII).

8 Note-se, entretanto, que tanto em Héli Chatelain quanto em Ferreira Diniz, a classificação geral dos povos de Angola assenta ainda tanto na terminologia «povos de raça negra», quanto no de «raça amarela», os chamados «bosquímanos», especificamente. Quando avalia os povos do sul de Angola, Chatelain propõe que as «[...] grandes tribos do distrito de Moçâmedes, exceptuando as da costa, já mencionadas, são: os Ba-Ngambue (Gambos), Ba-nianeka, Ba-londo, Ba-nkumbi, Hai, Jau, Ba-ximba e Ba-kubale. Para além do rio Cunene são os Kua-mati, Handa, Nyemba, Fende e os Ba-kankala da raça amarela Bochimanes». Por sua vez, ao tentar sintetizar os objectivos do seu estudo, Ferreira Diniz esclarece que o «[...] estudo etnográfico das tribus da província, distribuídas conforme o mapa aqui junto, não pode deixar dúvidas sobre a existência das duas raças indígenas - a Negra e a Boschjman - seja êle considerado, quer sob o ponto de vista dos caracteres étnicos, quer sob o ponto de vista da linguagem, da habitação, do vestuário, da alimentação, dos meios de existência, das faculdades intelectuais, quer enfim sob o ponto de vista da vida familiar ou da organização social» (DINIZ 1918: 495). Como se pode observar destes dois autores a sistemática conhecida por essa ocasião está ainda muito longe daquela que hoje tem sido apontada.

9 Em dois trabalhos produzidos e publicados em 1940, o diplomado pela Escola Superior Colonial e Administrador de circunscrição José Ribeiro da Cruz, introduz uma nova terminologia: os Bantu, tendo começado por esclarecer um facto inexistente nos dois 
autores anteriormente citados: «Os povos que habitam Angola (exceptuando os Boximanes, que fazem parte, ao sul da Colónia, da população da Província da Huila), pertencem ao grande grupo geográfico e linguístico Bantu» (1940a: 107) e ainda: "Os pequenos grupos dos bacancala, ba-cuisso, ba-curocas, ba-cuandos e ba-cassequéres, são povos Boximenes que os etnógrafos dizem ser os primitivos habitantes da África Equatorial e Austral» (1940b: 27). Portanto, temos com este autor uma sistemática que assenta na existência de povos de origem Bantu e povos Boximanes. Em relação aos primeiros explica que as «[...] 66 tribus dos Bantu, que vivem em Angola, formam dez grupos lingüísticos, a saber: «Kikongo, Kimbundo, Lunda-Kioko, Umbundu, Ganguela, Lunyaneka, Lunkhumbi, Xikuanyama, Xindonga $e$ Tyerero» (1940a: 108-112; 1940b: 23-27), devendo acrescentar-se os «Boximanes», que são «[...] considerados os primitivos habitantes da África Equatorial e Austral. Vagueiam em pequenos núcleos, no planalto da Huila, margens do rio Cunene e do Cubango. São de pequena estatura e a sua vida é miserável [...]» (1940a: 112), «e repelente» (1940b: 27).

Em 1943 aparece publicada a obra Raças do Império do antropólogo físico A. A. Mendes Corrêa, que se refere aos povos de «Angola e Congo» (pp. 403-485) e na qual apresenta uma curiosa carta étnica de Angola em que se destacam os povos que falam as línguas seguintes: "Quicongo, Quimbundo, Lunda-Quioco, Ganguela, Umbundo, Nhaneca, Humbe, Ovambo, Herrero, Vátua e Bochimane», sem contudo ser indicada a fonte utilizada. Seja como for, os recursos analíticos desde autor para caracterizar os povos de Angola são múltiplos desde a geografia física, passando pela arqueologia, a pré-história, a história e a antropologia física, até chegar à etnologia e a etnografia, onde destila um leque variado de considerações, tais como: «[...] Fala-se em prebantos, negros silvestres (de Johnston), negrilhos (um grupo de negrilhos da África central chamam-se Ba-tua, nome idêntico ao dado por Estermann a êste grupo angolense não-banto) enfim negros degenerados. Na verdade o seu estudo antropológico está por fazer» (CORRÊA 1943: 438). Não obstante tais considerações, começamos por encontrar já com este autor, um esboço de classificação em que se distinguem distintas tipologias e onde, pela primeira vez, se fala de «coi-san», isto é, «Bochimanes-Hotentotes» e "vátua» (CORRÊA 1943: 423). O agrupamento Vátua aparece assim pela primeira vez num esboço de classificação, mas, curiosamente, não logramos perceber qual é a fonte de informação deste autor. Não hesitamos em apontar o Padre Carlos Estermann, pelas considerações de Mendes Corrêa apontadas anteriormente. Mas essas atribuições, apesar da persistência pelos anos subsequentes, nunca farão sentido porque, como veremos em lugar apropriado, ignoram o sentido das atribuições da autoconsciência das pessoas e das comunidades.

11 Oito anos depois, em 1951, registamos a edição da obra Etnografia Angolana. Esboço para um estudo etnográfico de Mário Milheiros, um outro funcionário administrativo, que na sua introdução anota: «Podemos dividir as tribos de Angola, em sete grupos» (1951: 7) e para a sua explicitação propõe uma forma de ajuntamento algo estranha, para não dizer, desencontrada, em relação aos autores que o precederam. Observa-se isso sobretudo na forma administrativa como sugere os chamados agrupamentos tribais, não correspondendo assim a uma lógica que relacione língua, cultura, modalidade psíquica e território. Paradoxalmente, regista-se um avanço quando se refere ao sétimo grupo e escreve: «A este grupo pertencem as tribos de três sub-raças diferentes: boxímane, vátua e banta. Habitam as regiões de Porto Alexandre, Moçamedes, Chela, Baixo Cunene, Baixo Cubango, Cuando e Bundas e são: a) Sub-raça Boxímane (Khoisan ou boxímane-hotentote):!Cung - Missão da Quihita, em Quipungo e Hoque; Quede - Baixo Cunene (Mupa e Omupanda); b) Sub-raça Vátua: Ovacuepe - Porto Alexandre, Moçâmedes e Huila; Ovacuisse - Rios Bero, Giraúl, Bentiaba e entre o Deserto de Miçâmedes e a Serra da Chela; c) Sub-raça Banta, Ramo Cuvale: 
Cuvale (Huila e Moçâmedes); Chimba ou Himba (Gambos); Ova-Cuanhoca (Distrito da Huila), Ova-hacaona (Distrito da Huila), Ova-txavícua (Distrito da Huila), Ova-dombe (Moçâmedes e Huila), Ova-dimba (Distrito da Huíla); Ramo mestiço: Ba-cassequere (Moçâmedes), Ba-cuancala (Luchazes, Bundas e Cuando), Camaxis (Rio Cuando)» (MILHEIROS 1951: 11-12).

Esta obra de Mário Milheiros, teve uma segunda edição efectuada já sob os aupícios do Instituto de Investigação Científica de Angola (IICA) da qual foi investigador. No capítulo sobre a «Tipologia etno-linguística», Mário Milheiros escreve: «Podemos dividir as etnias de Angola, nos seguintes grupos etnolinguísticos: Quicongo, Quimbundo, Lunda-Quioco, Umbundo, Ganguela, Lunhaneca, Luncumbi, Cuanhama, Xindonga e Herero» (1967: 10-11), e, para meu espanto, paradoxalmente, não inclui os outros agrupamentos étnicos que já havia indicado na 1. edição desta sua obra: os "Boximanes» e os «Vátua». O que, sem sombra para dúvida, vai de encontro ao que escrevemos antes segundo a qual estamos perante um autor cujo trabalho está pejado de confusão e dúvidas.

13 Com efeito, podemos concluir que este trabalho de Mário Milheiros constitui um manancial de confusões cuja leitura não aconselho a nenhum leigo na matéria; não obstante não citar a sua fonte, tudo leva a crer que este autor tenha usufruído das informações dadas a estampa num artigo denominado «Os Vatwa», publicado pelo Padre Carlos Estermann na revista Mensário Administrativo (1951), justamente a instituição da administração colonial a que Mário Milheiros estava ligado.

Ainda nesta década, em 1955, com o estudo do etnólogo José Redinha, intitulado «Os povos de Angola $e$ as suas culturas", vemos surgir as primeiras ideias sobre uma sistemática mais alargada da organização geral dos povos em Angola (cf. REDINHA 1955: 1-65). Este estudo, publicado pelo Museu de Angola, antecipou o seu esboço de Distribuição étnica de Angola cuja redacção terminou em 1961, a que se lhe seguiu a impressão da 1. ${ }^{a}$ edição no ano seguinte igualmente pelo Mensário Administrativo. ${ }^{1} \mathrm{De}$ acordo com a sua classificação, José Redinha explica que as «[...] actuais populações autóctones angolanas são constituídas por Bantos, por alguns pré-Bantos e um número apreciável de não-Bantos. Os Bantos angolanos pertencem à grande divisão dos Bantos Ocidentais, conquanto haja a assinalar, no Sudoeste da Província, uma penetração relativamente extensa de Bantos Meridionais, atingindo para norte os Umbundos, até aos Bienos e Bailundos». Adianta ainda que a «composição étnica dos Bantos Ocidentais apresenta traços nigerianos $e$ camaroneses na sua zona noroeste, e fusões importantes de sangue etíope, e fortes marcas dos Camitas Orientais nos Grupos do Sudoeste» (REDINHA [1962], 1975: 7). Em relação às populações que denomina pré-Bantos, José Redinha considera que estes «apresentam importância muito fraca, habitando desde longa data as margens do rio Curoca, e uma faixa territorial pouco definida no deserto de Moçâmedes». Conclui afirmando que «formam, no seu conjunto, reduzido e rarefeito, o grupo Vatwa». Finalmente, anota que "as populações nãoBantas são constituídas pelos Bosquímanos ou Khoisan. Vivem em grupos avulsos, espécie de acampamentos temporários, nos territórios dos Bantos, na zona sul da Província, sendo o seu número da ordem dos cinco milhares de indivíduos» (REDINHA [1962], 1975: 7).

Em termos gerais e sistemáticos, as etnias angolanas actuais, escreve José Redinha, «dispostas segundo uma ordem cronológica das mais antigas para as mais recentes, apresentam o quadro seguinte:

Grupo Étnico Hotentote-Bosquímano (Não-Negro e não-Banto);

Grupo Étnico Vátua ou pré-Bantu;

Grupo Étnico Banto;

Grupo Étnico Europeu» (REDINHA [1962], 1975: 8). 
Em nosso entender, esta parece ter sido a primeira forma actualizada de organização apresentada sobre os povos de Angola. Tudo o que se vai seguir vai depender em grande medida desta proposta de Redinha, não obstante os esforços do IICA, surgidos poucos anos depois, não justifiquem esta nossa apreciação. Para melhor conhecimento do que pensamos, vai ser necessário compulsar todo o arquivo administrativo que eventualmente exista sobre esta questão específica e que julgamos muito importante para perceber o assunto.

Quanto a forma de organização interna, Redinha propõe que:

«O Grupo Étnico Hotentote-Bosquímano tem sido repartido por dois agrupamentos principais:

Mucuancalas e Cassequeles, ou Bosquímanos amarelos;

Cazamas ou Vazamas, ou Bosquímanos Negros» (id., ibidem).

«O Grupo Étnico Vátua ou pré-Banto é formado por Cuissis e Cuepes - algumas

vezes englobados na designação Curocas, derivada do Rio Curoca, cujas margens habitam» (id. ibidem).

18 Em relação ao Grupo Étnico Banto, Redinha chama a nossa atenção para o facto ser, «por grande diferença, a etnia demograficamente mais importante, e que a sua distribuição territorial abrange a totalidade da Província. Apresenta também em relação aos Koisan e aos Vátua, um estágio cultural mais avançado. [...] Por motivo da grande extensão geográfica que dominam, das influências de meios variados e de certas diferenças de expressão antropológica que lhes correspondem, a etnologia, apoiandose, aliás, em distinções estabelecidas pelas suas próprias comunidades autóctones entre si, estabeleceu para os Bantos Angolanos as sub-divisões étnicas seguintes:

Grupo Etnolinguístico Quicongo (Kikongu ou Conguês)

Grupo Etnolinguístico Quimbundo (Kimbundu ou Tymbundu)

Grupo Etnolinguístico Lunda-Quioco (Lunda-Kioco ou Lunda-Tshokwe)

Grupo Etnolinguístico Umbundo (ou Ovimbundu)

Grupo Etnolinguístico Ganguela (ou Ngangela)

Grupo Etnolinguístico Nhaneca-Humbe (ou Nyaneka-Lumkumbi)

Grupo Etnolinguístico Ambó (ou Vaambo também designado Xikwanyama)

Grupo Etnolinguístico Herero (ou Tjiherero)

Grupo Etnolinguístico Xindonga (ou Oshindonga).

19 Estes Grupos Etnolinguísticos fundamentam-se, como a sua própria designação indica, em diferenças de ordem linguística (sobre o fundo geral da língua banta) existentes entre os diversos grupos» (REDINHA [1962] 1975: 8).

Os estudos levados a cabo por José Redinha acerca das classificações étnicas dos povos de Angola, constituem, em relação aos materiais conhecidos anteriormente, um considerável avanço. Eles têm alcance em todo o contexto espacial da província de Angola e Redinha, no início desse seu estudo seminal, aponta claramente algumas das suas principais fontes, tais como o «Missionário e Etnógrafo Carlos Estermann para o Sudoeste de Angola, os do Coronel Hélio Esteves Felgas, para a Região Conguesa, os de Murray Childs para a área umbunda, e as nossas próprias documentações sobre o Nordeste e Leste, recolhidas no decurso da organização do Museu do Dundo» (REDINHA [1962] 1975: 5). Através dessa informação José Redinha mostra assim uma cobertura de conhecimentos julgados mais fiáveis porque partem de trabalhos de etnografia muito localizados e aprofundados sobre os principais "grupos étnicos» na Província de Angola. Não identifica, contudo, as suas fontes para os Kimbundu; observa-se, no entanto, que antes atribuiu-lhe sempre o designativo Ambundo e agora chama-lhe unicamente os 
Kimbundu, o que nos parece constituir um avanço digno de registo. Mas os esclarecimentos acerca dessa mudança estão por fazer.

Contudo, apesar desses esforços, José Redinha não logra explicar também as razões da designação do «Grupo Xindonga» para reunir o conjunto das populações que habitam ao sul do então "Distrito do Cuando Cubango», na fronteira com o antigo Sudoeste Africano, hoje Namíbia.

Observa-se que as décadas de 1960 e 1970 trazem um novo sopro no desenvolvimento dos estudos etnográficos e etnológicos em Angola, com o surgimento do Instituto de Investigação Científica de Angola (IICA), nomeadamente o seu Departamento de Etnologia e Etnografia, e com ele alguns profissionais como o etnólogo Carlos Lopes Cardoso que começou por o dirigir, o próprio José Redinha e Mesquitela Lima experientes profissionais cuja actividade teve origem no seio da Companhia de Diamantes de Angola (DIAMANG). Outros nomes farão percurso no início da década de 1970, tais como José de Sousa Bettencourt, José Cortez, Borges do Canto, Lino da Silva e Ana de Sousa Santos que, certamente, juntos terão contribuído para melhorar em termos técnicos as apreciações sobre as divisões étnicas de Angola. Entretanto, do lado das instituições missionárias, católicas e protestantes, surgem importantes contributos que virão enriquecer o quadro de conhecimentos sobre os povos da província de Angola.

23 Assim, Carta Étnica de Angola (Esboço) é o título de um estudo breve, não datado, subscrito por Mesquitela Lima, então Conservador do Museu de Angola e 1.․ Assistente no IICA; o mesmo explica que essa Carta «[...] foi esboçada nos anos 1962/63 pelo então responsável da Divisão de Etnologia e Etnografia do Instituto de Investigação Científica de Angola, Dr. Carlos Lopes Cardoso. Ela veio sempre sendo completada com elementos que iam entrando no departamento e, em 1964, foi publicado por nós, com ligeiras alterações, no fascículo n.. 5 da enciclopédia "Focus", editada pela livraria Sá da Costa, Lisboa». Terá sido este o documento que foi utilizado pelo historiador francês René Pélissier? Pouco sabemos, pois na sua obra este autor aponta a data de 1964 e este que citamos não está datado.

Pode observar-se que neste documento, tanto quanto na proposta de José Redinha, encontramos o registo de um Grupo Xindonga, que reúne os povos «Cuangares, Candundos, Cussos, Vanhengos e Diricos», mas há pouca ou quase nenhuma informação acerca da origem desse designativo étnico. A este propósito, convém notar que o já citado historiador francês René Pélissier, utilizando um texto de Mesquitela Lima datado de 1970, em vez de «Xindonga» chama-lhe «Grupo Okavango» e observa judiciosamente em nota: «Parece que a área étnica dos Okavangos é, na realidade, muito menor; e certos autores consideram mesmo que este grupo é artificial» (PÉLISSIER 1986, II: 337).

Ora, como se sabe, Okavango é a designação do rio no contexto fora das fronteiras de Angola, nomeadamente na Namíbia (que atravessa a Faixa de Caprivi) e no coração do Botswana, onde vai desaguar. Trata-se, certamente, de uma forma de designar entre nós o rio Kuvango, uma variante dialectal, que tem uma grande influência para as populações da região sudeste do nosso país. Com efeito, na República da Namíbia, as populações que estão a sul desse rio são geralmente classificadas como sendo «the Kavango tribes» e essa classificação reagrupa populações do grupo San (!Xu e Mbarakwengo) e do grupo Bantu (Mbukushu, Gciriku, Shambiu, Mbunza e Kwangali), estimados em cerca de 140000 pessoas (cf. MALAN 1999: 35-54). 

IICA é o etnólogo João Vicente Martins, um experiente investigador que começou também por trabalhar nas minas da Empresa de Diamantes de Angola (DIAMANG), e que mais tarde viria a publicar alguns ensaios e uma tese de doutoramento sobre a cultura dos povos Ruund (Lunda) e Cokwe do Nordeste de Angola. Apesar da informação cartográfica que utiliza ser originário do IICA, ele o fez também a partir da informação veiculada pelo Museu Nacional de Antropologia de Luanda, uma instituição museal surgida nos alvores da independência de Angola e de que dele falaremos numa outra ocasião (cf. MARTINS 1993: 32 e seguinte, não paginada; 2001: 140-141; 2008: 390-391).

\section{Algumas notas a guisa de conclusão}

Pudemos observar assim que os povos que habitam Angola foram ao longo dos tempos considerados «tribos», «etnias», «grupos étnicos», mas os levantamentos produzidos não testemunham correctamente a realidade, já que na sua grande maioria as informações reproduzidas na «Carta étnica de Angola» constituem uma autêntica ilusão. Encontramos «bosquímanos» ou «bochimanes», «hotentotes», grupos «não negro», grupos «não banto», «grupo étnico vátua ou pré-bantu», enfim, uma série de designativos que não correspondem a realidade, por um lado porque não respeitarem as atribuições que são dadas pelos próprios povos (isto é, a sua autoconsciência étnica), por outro porque estão registados na maior parte dos casos designativos que são dados por povos vizinhos, atribuições essas que são, na maior parte das vezes, indicativos de escárnio, desconhecimento, troça ou todo o tipo de menosprezo criados especificamente pelas entidades coloniais para designar tais povos. 
Padre Carlos Estermann, um dos principais autores apontado pelo etnólogo José Redinha como constituindo uma fonte insuspeita, num artigo de extraordinária magnitude, mostra com grande clareza que o «problema da diferenciação étnica em Angola» constituia na época uma preocupação e que, do ponto de vista metodológico, quem quisesse saber «quantas tribos, ou pelo menos quantos grupos étnicos existem em Angola?» ou «Quais são as suas designações étnicas?», teria que ter em conta pelo menos duas coisas: em primeiro lugar, «o reconhecimento linguístico que abranja toda a área da província, não se vê como possa merecer mais confiança do que o étnico»; em segundo lugar, «Nem sempre pode empregar-se este critério para determinar o substracto étnico dum povo. Noutras palavras: pode um grupo étnico falar um idioma que pertence propriamente a um agregado rácico diferente. [...] Há, por exemplo, a viverem no meio dos Cuanhamas e à maneira deles pequenos núcleos "kedes", que já não sabem falar outra língua que a dos seus vizinhos. No entanto racicamente diferem completamente deles. Não há pois que ver, em rigor cientifico, quando nos queremos referir a etnias e proceder a estudos».

31

Concluimos esta primeira parte anotando que com o presente artigo nos contentamos unicamente em efectuar um breve levantamento acerca da classificação étnica dos povos de Angola durante o período colonial. No entanto, é nossa intenção reflectir igualmente acerca da sua utilização no período pós-independente de Angola, e que o faremos na segunda parte do nosso levantamento, enquanto que, em definitivo, reservaremos à reflexão e crítica e apontaremos o que pensamos especificamente sobre esta problemática num terceiro trabalho.

\section{BIBLIOGRAFIA}

ATLAS, 1962, Atlas Missionário Português. Prefácio de A. da Silva Rego. Lisboa, Missão para o Estudo da Missionologia Africana; Centro de Estudos Políticos e Sociais da Junta de Investigações do Ultramar, 180p.

ATLAS, 1964 (2. edição), Atlas Missionário Português. Prefácio de A. da Silva Rego e Eduardo dos Santos. Lisboa, Junta de Investigações do Ultramar e Centro de Estudos Históricos Ultramarinos, 198p.

ALMEIDA António de, 1994, Os Bosquímanos de Angola. Apresentação de J. A. Cruz e Silva. Lisboa, Instituto de Investigação Científica Tropical, 404p.

CARDOSO Carlos Lopes (dir.), 1962-1963, Carta étnica de Angola. Esboço. Luanda, Divisão de Etnologia e Etnografia do Instituto de Investigação Científica de Angola (IICA) [stencilado].

CHATELAIN Héli, 1964, Contos populares de Angola. Cinquenta contos em Quimbundo coligidos e anotados por Héli Chatelain. Edição portuguesa dirigida e orientada por Fernando de Castro Pires de Lima; palavras prévias de A. A. Mendes Corrêa; prólogo de Fernando de Castro Pires de Lima; tradução do inglês por M. Garcia da Silva; revisão do texto por Ilídio da Silva Lopes. Lisboa, Agência-Geral do Ultramar, 572p.

CHILDS Gladwyn Murray, 1949, Umbundu kinship \& character. Being a description of the social structure and individual development of the Ovimbundu of Angola, with observations concerning the 
bearing on the enterprise of Christian Missions of certain phases of the life and culture described. Londres, New York, Toronto, International African Institute and the Witwatersrand University Press, 246p. CORRÊA A. A. Mendes, 1943, Raças do império. Porto, Portucalense Editora, 626p.

CRUZ José Ribeiro da, 1940a, Geografia de Angola. Física - Económica - Política. Prefácio do autor. Lisboa, Sociedade Industrial de Tipografia, Lda., 244p.

CRUZ José Ribeiro da, 1940b, Notas de Etnografia Angolana. Prefácio do autor. Lisboa, Lisboa, Sociedade Industrial de Tipografia, Lda., 182p.

DINIZ José de Oliveira Ferreira, 1918, Populações indígenas de Angola. Introdução do autor. Coimbra, Imprensa da Universidade, 756p.

ESTERMANN Padre Carlos, 1951, «Os Vatwa», Mensário Administrativo (Luanda), n. ${ }^{\circ}$ 49-50.

ESTERMANN Padre Carlos, 1983, Etnografia de Angola (Sudoeste e Centro). Colectânea de artigos dispersos. Volume I, coligidos por Geraldes Pereira. Apresentação de Manuel Viegas Guerreiro. Lisboa, Instituto de Investigação Científica Tropical, 486p.

ESTERMANN Padre Carlos, 1983, Etnografia de Angola (Sudoeste e Centro). Colectânea de artigos dispersos. Volume II, coligidos por Geraldes Pereira. Apresentação de Manuel Viegas Guerreiro. Lisboa, Instituto de Investigação Científica Tropical, 524p.

FELGAS Hélio, 1960, «Esboço etnográfico dos indígenas do Congo Português», Mensário Administrativo (Luanda), n. ${ }^{\text {os }}$ 149-154, Janeiro-Julho.

GUERREIRO Manuel Viegas, 1968, Bochimanes !Khũ de Angola. Prefácio do autor. Luanda, Instituto de Investigação Científica de Angola; Lisboa, Junta de Investigações do Ultramar, 390p.

LIMA Mesquitela, s.d. [1970?], Carta Étnica de Angola (Esboço). Luanda, Instituto de Investigação Científica de Angola, n. p. [stencilado].

MAGALHÃES Padre António Miranda, 1922, Manual de línguas indígenas de Angola. Luanda, Imprensa Nacional de Angola, 202p.

MALAN J. S., 1999 (2. edição), Peoples of Namibia. Prefácio de J. E. Saayman. Pretoria, Rhino Publishers, 152p.

MARTINS João Vicente, 1993, Crenças, adivinhação e medicina tradicionais dos Tutchokwe do Nordeste de Angola. Lisboa, Instituto de Investigação Científica Tropical, 484p + 110p.

MARTINS João Vicente, 2001, Os Tutchokwe do Nordeste de Angola. Lisboa, Instituto de Investigação Científica Tropical, 562p.

MARTINS João Vicente, 2008, Os Bakongo ou Tukongo do Nordeste de Angola. Lisboa, Imprensa Nacional-Casa da Moeda, 426p.

MILHEIROS Mário, 1951, Etnografia Angolana. Esboço para um estudo etnográfico. Luanda, Edição do «Mensário Administrativo» Angola, 224p.

MILHEIROS Mário, 1967 (2. a edição, corrigida e anotada), Notas de Etnografia Angolana. Prefácio do autor. Luanda, Instituto de Investigação Científica de Angola, 184p.

PAUTA ETNOGRÁFICA, 1960, Pauta etnográfica. Censo da população de 1960. Luanda, Direcção dos Serviços de Economia e Estatística Geral.

PÉLISSIER René, 1977, Les guerres grises. Résistance et révoltes en Angola (1845-1941). MontametsOrgeval, Éditions Pélissier, 632p. 
PÉLISSIER René, 1978, La colonie du minotaure. Nationalismes et révoltes en Angola (1926-1961).

Montamets-Orgeval, Éditions Pélissier, 728p.

PÉLISSIER René, 1986, História das campanhas de Angola. Resistência e revoltas, 1845-1941, volume I. Tradução de Manuel Ruas. Lisboa, Editorial Estampa, 400p. [«Imprensa universitária»; 50]

PÉLISSIER René, 1986, História das campanhas de Angola. Resistência e revoltas, 1845-1941, volume II. Tradução de Manuel Ruas. Lisboa, Editorial Estampa, 436p. [«Imprensa universitária»; 51]

REDINHA José, 1955, «Os Povos de Angola e as suas culturas», in Colecção etnográfica. Luanda, Museu de Angola [«Publicações do Museu de Angola»], pp. 1-66.

REDINHA José, 1975, Etnias e culturas de Angola. Luanda, Instituto de Investigação Científica de Angola e Banco de Angola, 448p.

\section{NOTAS}

1. Afigura-se-nos conveniente esclarecer que Mensário Administrativo designava por um lado uma editora e por outro o título de uma revista. Neste caso específico, referimo-nos à revista onde, pela primeira vez, foi publicado este texto de José Redinha.

\section{RESUMOS}

O objectivo do presente artigo é efectuar um levantamento sobre a "classificação étnica» dos povos de Angola durante o período colonial, recuperar e agrupar o máximo de informação escrita existente sobre o assunto. Essa classificação, efectuada sobretudo durante o século XX - o que equivale dizer, durante o início da histórica fase de implantação do colonialismo português em Angola, e posteriormente, na sua fase de desenvolvimento -, foi efectuada em múltiplas fases ou períodos por diversos profissionais da administração portuguesa, pelo prelado, sobretudo católico, e por alguns pesquisadores das ciências sociais, apareceu, numa primeira fase, agregado aos objectivos da política colonial de dominação dos povos «primitivos» e «selvagens» encontrados em Angola, e, numa segunda fase, reunidos que estavam os elementos e dados essenciais que lhes permitiu agregar esses povos em «tribos» e/ou «grupos étnicos» e conhecer as suas tendências e práticas, a de utilização da informação para melhor governar, utilizando uma prática comum de subjugação dos povos, isto é, a de «dividir para melhor reinar». A produção do presente artigo afigurou-se-nos igualmente necessário, pois, do ponto de vista histórico e até conceptual, no período pós-independente, foi-se assistindo à produção de estudos baseados em informações pouco consistentes acerca dessas mesmas classificações, completamente despidos de ordenamento e bases históricas, que, em meu entender, acabam por toldar não apenas o espírito crítico pretendido e necessário a qualquer estudo deste tipo, mas também, e sobretudo, a sua objectividade.

The purpose of this article is to carry out a survey on the 'ethnicity' of the people of Angola during the colonial era, retrieve and collate as much information existing written on the subject. This classification, carried out mainly during the twentieth century - which is to say, during the beginning of the historical deployment phase of Portuguese colonialism in Angola, and later in 
its development phase - was conducted in multiple stages or periods by several professionals of the Portuguese administration, the prelate, especially Catholic, and some researchers from the social sciences, appeared initially to be added to the objectives of colonial policy of domination of "primitive» and «savage» people found in Angola. On a second phase, gathered the essential elements and data that allowed them to add these people in «tribes» and/or «ethnic groups» and know their tendencies and practices, was the use of information to better govern, using a common subjugation practice of peoples, that is, «divide to better rule». This article appeared to us also necessary because, from a historical point of view and even conceptual, post-independent period watched the came out of several studies based on inconsistent information about these same classifications, completely stripped of planning and historical basis, which, in my opinion, ultimately overshadow not only the intended and necessary critical spirit to any study of this kind, but also, and above all, their objectivity.

\section{ÍNDICE}

Palavras-chave: «Carta étnica de Angola», classificação étnica, classificação etnográfica, diversidade étnica, estudos antropológicos e etnográficos, etnias, grupos étnicos, tribos, «primitivos», «selvagens», «indígenas»

Keywords: «Ethnic Charter of Angola», ethnicity, ethnographic classification, ethnic, anthropological and ethnographic studies, ethnic groups, tribes, «primitive», «savages», «indigenous»

\section{AUTOR}

\section{VIRGÍLIO COELHO}

virgiliocoelho@hotmail.com

virgiliocrcoelho@gmail.com

Professor Auxiliar do Departamento de Antropologia da Faculdade de Ciências Sociais (FCS) da Universidade Agostinho Neto (UAN) e Coordenador Adjunto do Centro Avançado de Estudos Africanos (CAEA) da FCS e Assessor Principal do Ministério da Cultura.

Professor Auxiliar do Departamento de Antropologia (DA) da Faculdade de Ciências Sociais (FCS) da Universidade Agostinho Neto (UAN), é antropológo, diplomado pela École Pratique des Hautes Études (EPHE), Universidade de Paris - Sorbonne (França), tendo apresentado a tese intitulada La place des jumeaux dans le système religieux des Ndongo (Ambundu), Angola (523p.), onde também efectuou estudos doutorais em Antropologia Social e Cultural, sob a direcção do Prof. Doutor Michel Cartry. Concluiu o mestrado: Diplôme d'études approfondis (DEA), na especialidade de «Anthropologie comparée des Religions d'Afrique, d'Orient et d'Extreme Orient», em 1988, sob a direcção da Prof." Doutora Jacqueline Duvernay-Bolens, tendo submetido a tese Le culte des "génies» ítùtà chez les Ndongo de la valée du Kwanza, Angola (176p.). É investigador (Assessor Principal) do Ministério da Cultura, onde dirigiu algumas das suas instituições, dentre as quais o Departamento de Folclore da Direcção Nacional de Arte (DINARTE) e a Delegação Provincial de Luanda (DPL). De Janeiro de 2003 a Setembro de 2008, foi ViceMinistro da Cultura para o Património e a investigação científica, no âmbito do Governo de unidade e reconciliação nacional (GURN). No âmbito do ensino, é docente no curso de Antropologia do Departamento de Antropologia da Faculdade de Ciências Sociais (FCS) da Universidade Agostinho Neto (UAN), orientando formação nas cadeiras seguintes: Introdução à Antropologia; Etnologia Geral; Semiótica e Semiologia; Tradições Orais, Mitos e Mitologias; 
Antropologia das Religiões; Epistemologias Antropológicas e Teorias Antropológicas. As suas principais áreas de investigação são a antropologia social e cultural (estudos de parentesco e de organização social), de antropologia política (questões específicas sobre a problemática do Estado em África, nação, etnia e etnicidade, tribo, identidade cultural e alteridades, etc.), de antropologia do simbólico, antropologia histórica, antropologia e geografia linguística e de antropologia da literatura e artes em Angola; e ainda, a antropologia das religiões em África (África central, oriental e austral, particularmente em Angola). É membro correspondente da Academia das Ciências de Lisboa, membro da Associação de Antropólogos e Sociólogos de Angola (AASA), onde desempenha as funções de Secretário do Pelouro de Pesquisas e Conferências do seu Comité Executivo e vice-presidente do Conselho Editorial e Secretário da Ngola - Revista de Estudos Sociais da AASA; na sua qualidade de artista plástico, é membro fundador da União Nacional dos Artistas Plásticos (UNAC), tendo dirigido a sua Mesa da Assembleia Geral no período de 2005 a 2009; e membro da União dos Escritores Angolanos (UEA). Jornalista, desempenhou funções no suplemento dominical Vida \& Cultura (e posteriormente Vida Cultural) do Jornal de Angola e foi coordenador da secção «Cultura» do jornal Angolense e, posteriormente, do jornal Semanário Angolense. É actualmente Director das Edições Mulemba, editora da FCS da UAN e editor das seguintes revistas: Mulemba - Revista Angolana de Ciências Sociais, órgão científico da FCS da UAN; Maka - Revista de Literatura \& Artes, da União dos Escritores Angolanos (UEA) e Ngola - Revista de Estudos Sociais, órgão da Associação de Sociólogos e Antropólogos de Angola (AASA), integrando os seus conselhos científicos e editoriais. É igualmente membro dos Conselhos Científicos das revistas seguintes: África - Revista do Centro de Estudos Africanos da Universidade de São Paulo (Brasil), Cadernos de Estudos Africanos, revista do Centro de Estudos Africanos do ISCTE - Instituto Superior das Ciências do Trabalho e da Empresa (Lisboa, Portugal), e do Conselho Editorial da RAS - Revista Angolana de Sociologia, da Sociedade Angolana de Sociologia (SAS). Em 2010 foi-lhe outorgado o «Prémio Nacional de Cultura e Artes», na secção de Ciências Humanas e Sociais, pelas obras «Em busca de Kábàsà!...» Estudos e reflexões sobre o «Reino» do Ndòngò. Contribuições para a História de Angola e Os Túmúndòngò, os «génios» da natureza e o Kílàmbà. Estudos sobre a sociedade e a cultura kímbùndù. 